\title{
EFICIÊNCIA DE INSTRUMENTOS ROTATÓRIOS NO RETRATAMENTO ENDODÔNTICO.
}

Carolina Araujo AMATUZZI; Juarez GARCIA; Jacqueline BALDINI; Luis Fernando FARINIUK; Camilla REHDER.

O presente trabalho teve como objetivo avaliar a capacidade de remoção da gutapercha promovida pela ação dos instrumentos Profile, ProTaper, GT, K3 Endo, Hero e limas tipo K. Foram utilizados 60 dentes pré-molares inferiores humanos que foram preparados utilizando-se as limas GT rotatórias. Os espécimes foram obturados e os seguintes dados foram avaliados: tempo de remoção da guta-percha, quantidade remanescente de material obturador nas paredes dos canais, com auxílio do Programa Image Tool, e fratura dos instrumentos. A análise foi realizada utilizando a análise de variância, seguida do teste de comparações múltiplas de Games-Howell. A técnica que removeu mais rapidamente o material obturador foi o grupo ProFile e K3, seguido do grupo ProTaper, GT e Hero, sendo o mais demorado o grupo manual $(p<0,05)$. O grupo GT apresentou a menor quantidade de material obturador remanescente seguido dos grupos ProFile, Protaper, K3, Hero e manual. Com relação à fratura observou-se 2 fraturas e 1 deformação no grupo ProTaper, 1 no grupo manual e 1 do grupo GT. Os instrumentos estudados podem ser ordenados em ordem crescente quanto à capacidade de remoção de material obturador: manual, Hero, K3, ProTaper, ProFile e GT. O grupo manual diferiu de todos os grupos, apresentando o maior tempo para remoção do material obturador. 